\title{
Carboxylate-Assisted Formation of Aryl-Co(III) Masked-Carbenes in Cobalt-catalyzed C-H Functionalization with Diazo Esters
}

\author{
Oriol Planas, ${ }^{\dagger}$ Steven Roldán-Gómez, ${ }^{\dagger}$ Vlad Martin-Diaconescu, ${ }^{\dagger}$ Teodor Parella, ${ }^{\ddagger}$ Josep M. \\ Luis, ${ }^{+}$Anna Company, ${ }^{+}$Xavi Ribas ${ }^{+*}$ \\ †Institut de Química Computacional i Catàlisi (IQCC) and Departament de Química, Universitat de Girona, \\ Campus Montilivi, Girona, E-17003, Catalonia, Spain \\ ‡Servei de RMN, Facultat de Ciències, Universitat Autònoma de Barcelona, Campus UAB, Bellaterra, E-08193 \\ Catalonia, Spain \\ Supporting Information Placeholder
}

\begin{abstract}
Herein we describe the synthesis of a family of aryl-Co(III)-carboxylate complexes and their reactivity with ethyl diazoacetate (EDA). Crystallographic, full spectroscopic characterization and theoretical evidence of unique C-metalated aryl-Co(III) enolate intermediates is provided, unraveling a carboxylate-assisted formation of aryl-Co(III) masked-carbenes. Moreover, additional evidence for an unprecedented Co(III)-mediated intramolecular SN2-type C-C bond formation in which the carboxylate moiety acts as a relay is disclosed. This novel strategy is key to tame the hot reactivity of a metastable $\mathrm{Co}(\mathrm{III})$-carbene and elicit $\mathrm{C}-\mathrm{C}$ coupling products in a productive manner.
\end{abstract}

\section{INTRODUCTION}

Directed C-H functionalization methodologies using non-precious earth-abundant $3 \mathrm{~d}$ transition metal catalysts are currently attracting increasing attention. ${ }^{1}$ In particular, high-valent cobalt catalysis has emerged as a valuable approach for the construction of a wide variety of organic molecules, mainly due to the highly polarized character of C-Co bonds when compared to the other group 9 neighbours. ${ }^{2}$ Among the vast array of possible transformations, the use of diazocarbonyl compounds as coupling partners constitutes a particularly attractive method due to their wide application as precursors for several metal-catalyzed processes, ${ }^{3}$ including cyclopropanation $^{4}$ and functionalization of inert $\mathrm{C}-\mathrm{H}$ bonds. ${ }^{5}$ Although Co-carbene have been extensively studied, ${ }^{6}$ directed $\mathrm{C}-\mathrm{H}$ functionalization involving high-valent aryl-Co-carbene intermediates is still in its infancy and their mechanistic understanding is based on limited experimental evidences as well as computational studies. $^{7}$

The synthesis of organometallic Co(III) species through $\mathrm{C}-\mathrm{H}$ activation is challenging and still remains underdeveloped. ${ }^{8}$ Legg and co-workers made the first contribution to the field being able to isolate an organometallic alkyl-Co(III) complex through C-H activation starting from $\mathrm{Co}(\mathrm{II})$ salts and characterizing several intermediates in a step-wise manner. ${ }^{8 d, e}$ In our commitment to unravel key intermediates, ${ }^{9}$ our group has recently published the synthesis and characterization of a family of aryl-Co(III) complexes through C-H activation, ${ }^{10}$ taking advantage of the enhanced stability offered by a macrocyclic model substrate which has proven to stabilize other organometallic high-valent aryl/alkyl-metal intermediate species. ${ }^{11}$ These complexes proved to be catalytically competent during alkyne annulation reactions, furnishing either 5- or 6-membered ring products (Scheme 1, blue). Taking into account the increasing attention to the use of carbene surrogates for C$\mathrm{C}$ bond formation reactions, we became interested in the reactivity of our previously reported aryl-Co(III) complexes towards diazo esters to elucidate the operative mechanism as well as the nature of the key intermediates (Scheme 1, red).

Scheme 1. Previous work with alkynes as coupling partners (top, blue) and current study disclosing the reactivity of aryl-Co(III) complexes towards diazo esters (down, red). 


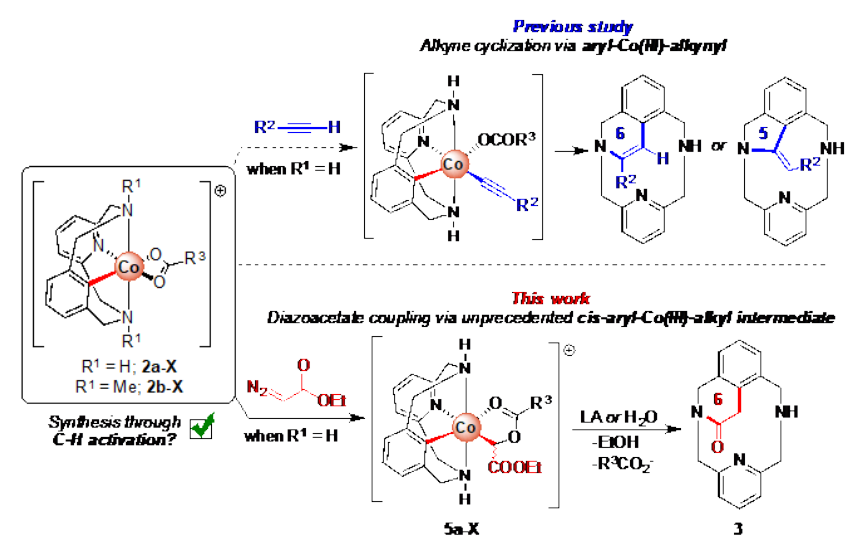

Herein we describe the synthesis of a new family of aryl$\mathrm{Co}(\mathrm{III})$-carboxylate complexes (2a-X) and their reactivity with ethyl diazoacetate (EDA). Crystallographic, spectroscopic and theoretical evidences of a unique Cmetalated cis-aryl-Co(III)-alkyl enolate intermediate are provided, unveiling a novel strategy to tame the hot reactivity of cobalt-carbenes and construct C-C bonds through an unusual intramolecular $S_{N} 2$-like pathway. Theoretical studies show the feasibility of this transformation, in which Lewis acids play an important role turning the carboxylate moiety into a better leaving group.

\section{RESULTS}

Stoichiometric Annulation Reaction with EDA. Initially, we attempted to perform the stoichiometric annulation reaction of the previously reported aryl-Co(III) complex 2a-OAc with 2.0 equiv of EDA. ${ }^{10}$ When the reaction was performed using ethanol, no reaction was observed (Table 1, entry 1). However, the use of fluorinated alcohols was beneficial for the formation of macrocyclic amide 3 (Table 1, entries 2-3). In addition, reaction with the arylCo(III) complex bearing methylated tertiary amines, $\mathbf{2 b -}$ OAc, was not successful and only trace amounts of product 4 were detected by HRMS (4 corresponds to the $\mathrm{C}-\mathrm{C}$ coupling product with no intramolecular reorganization, see Scheme S5).

Table 1. Evaluation of stoichiometric reaction conditions. ${ }^{12}$

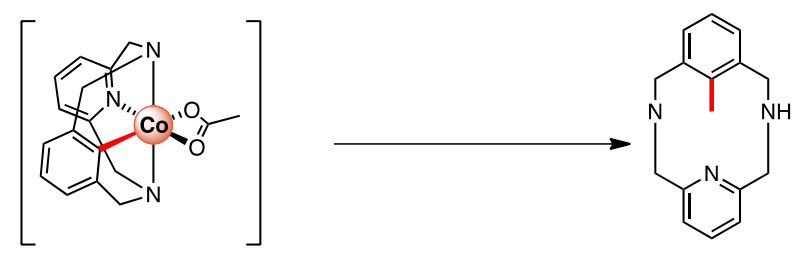

\begin{tabular}{cccc}
\hline entry & additives (equiv.) & solvent & yield of 3 (\%) \\
\hline 1 & none & EtOH & $0 \%$ \\
2 & none & TFE $^{\mathrm{b}}$ & $10 \%$ \\
3 & none & $\mathrm{HFIPc}^{\mathrm{a}}$ & $31 \%$ \\
4 & $\mathrm{AcOH}(1.0)$ & $\mathrm{TFE}$ & $15 \%{ }^{\mathrm{d}}$ \\
5 & $\mathrm{H}_{2} \mathrm{O}(1.0)$ & $\mathrm{TFE}$ & $57 \%$ \\
\hline
\end{tabular}

\begin{tabular}{|c|c|c|c|}
\hline 6 & $\mathrm{H}_{2} \mathrm{O}(2.0)$ & TFE & $82 \%$ \\
\hline 7 & $\mathrm{H}_{2} \mathrm{O}(4.0)$ & TFE & $96 \%(91 \%)^{\mathrm{e}}$ \\
\hline 8 & $\operatorname{Mg}(\mathrm{OTf})_{2}(1.0)$ & TFE & $67 \%$ \\
\hline 9 & $\begin{array}{c}\mathrm{H}_{2} \mathrm{O}(1.0)+\mathrm{Mg}(\mathrm{OTf})_{2} \\
(1.0)\end{array}$ & TFE & $92 \%(87 \%)^{\mathrm{e}}$ \\
\hline 10 & $\mathrm{Li}(\mathrm{OTf})(1.0)$ & TFE & $95 \%(88 \%)^{e}$ \\
\hline 11 & $\mathrm{H}_{2} \mathrm{O}(4.0)$ & $\mathrm{EtOH}$ & $88 \%$ \\
\hline 12 & $\mathrm{Li}(\mathrm{OTf})(1.0)$ & $\mathrm{EtOH}$ & $91 \%$ \\
\hline
\end{tabular}

a Yield determined using 1,3,5-trimethoxybenzene as internal standard. b2,2,2-trifluoroethanol (TFE). c1,1,1,3,3,3-hexafluoro-2propanol (HFIP). dProto-demetalation of 2a-OAc was observed. eIsolated yield.

A variety of commonly used proton sources were investigated as additives. Unfortunately, acetic acid was not successful (Table 1, entry 4), mainly showing protodemetalation of the starting 2a-OAc complex. However, water as additive was proven to be effective, and $\mathbf{3}$ was obtained in $91 \%$ isolated yield when 4.0 equiv of $\mathrm{H}_{2} \mathrm{O}$ were added (Table 1, entry 7). To gain more insight into the reaction mechanism, a variety of Lewis acids (LA) were tested as additives (Table 1, entries 8-10), as they proved to be beneficial in other methodologies using cobalt as catalysts. ${ }^{7 e}$ Interestingly, the addition of 1.0 equiv of $\mathrm{Mg}(\mathrm{OTf})_{2}$ allowed the formation of 3 in $67 \%$ yield. Furthermore, when 1.0 equiv of both $\mathrm{Mg}(\mathrm{OTf})_{2}$ and $\mathrm{H}_{2} \mathrm{O}$ were added, 3 was obtained in $92 \%$ yield. Finally, when a stronger Lewis acid such as $\mathrm{Li}(\mathrm{OTf})$ was used in absence of water, 3 was obtained in 95\% yield. If $\mathrm{H}_{2} \mathrm{O}$ or $\mathrm{Li}(\mathrm{OTf})$ were used as additives, 3 was also formed in good yields using EtOH as solvent (Table 1, entries 11-12).

Catalytic Annulation Reaction with EDA. The annulation reaction was also studied in a catalytic fashion (Table 2). EDA was successfully coupled with $\mathbf{1 a}-\mathbf{H}$ using $\mathbf{2 a - O A c}$ as catalyst $(20 \mathrm{~mol} \%)$, under air in TFE with 4.0 equiv of $\mathrm{H}_{2} \mathrm{O}$, forming 3 in $93 \%$ yield (Table 2, entry 2). Product 3 was also obtained in excellent yield (Table 2, entry 3 ) under an inert atmosphere $\left(\mathrm{N}_{2}\right)$ using $\mathbf{2 a - O A c}$ as catalyst, indicating a redox neutral mechanism where $\mathrm{Co}(\mathrm{III})$ does not change its oxidation state. The role of external oxidants was evaluated performing the catalysis with readily available $\mathrm{Co}(\mathrm{II})$ salts. When $20 \mathrm{~mol} \%$ of $\mathrm{Co}(\mathrm{OAc})_{2}$ was used under air (Table 2, entry 4), 3 was obtained in $96 \%$ yield. On the other hand, under an inert atmosphere reactivity was completely inhibited (Table 2, entry 5), thus indicating that $\mathrm{Co}$ (III) species are required to effect the C-H activation to form 2a-OAc. ${ }^{11}$ Moreover, additives have also proven to be essential in catalysis (Table 2, entries 6-9). Thus, when 1a-H was reacted with EDA using $\mathrm{Co}(\mathrm{OAc})_{2}$ as catalyst without water, only a $15 \%$ yield was obtained. However, as it was previously observed in the stoichiometric reaction, when $\mathbf{1 a}-\mathbf{H}$ was reacted with EDA in presence of 1.0 equiv of $\mathrm{Mg}(\mathrm{OTf})_{2}$ using $\mathrm{Co}(\mathrm{OAc})_{2}$ as catalysts, $42 \%$ yield of 3 was obtained 
(Table 2, entry 7). Interestingly, a cooperative effect between $\mathrm{Mg}(\mathrm{OTf})_{2}$ and $\mathrm{H}_{2} \mathrm{O}$ can be observed when 1.0 equiv of each of them is added, obtaining 3 in a $93 \%$ yield (Table 2, entry 8). Furthermore, when 1.0 equiv of $\mathrm{Li}(\mathrm{OTf})$ was added as additive in absence of water, $\mathbf{3}$ was obtained in $96 \%$ yield, which indicate the key role of Lewis acids in the reaction.

Table 2. Evaluation of catalytic reaction conditions. ${ }^{13}$

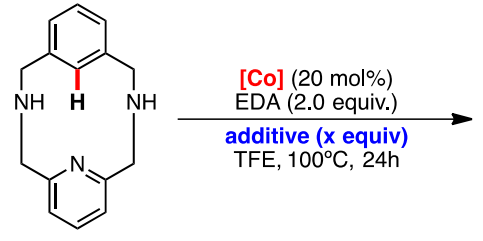

1a-H

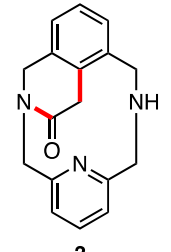

\begin{tabular}{cccc}
\hline entry & {$[\mathrm{Co}]$} & additive (equiv.) & yield of $\mathbf{3}(\%)^{\mathrm{a}}$ \\
\hline 1 & - & $\mathrm{H}_{2} \mathrm{O}(4.0)$ & n.r. \\
2 & 2a-OAc & $\mathrm{H}_{2} \mathrm{O}(4.0)$ & $93 \%(87 \%)^{\mathrm{b}}$ \\
$3^{\mathrm{c}}$ & $\mathbf{2 a - O A c}$ & $\mathrm{H}_{2} \mathrm{O}(4.0)$ & $95 \%(84 \%)^{\mathrm{b}}$ \\
4 & $\mathrm{Co}(\mathrm{OAc})_{2}$ & $\mathrm{H}_{2} \mathrm{O}(4.0)$ & $\mathbf{9 6 \%}(\mathbf{8 9} \%)^{\mathrm{b}}$ \\
$5^{\mathrm{c}}$ & $\mathrm{Co}(\mathrm{OAc})_{2}$ & $\mathrm{H}_{2} \mathrm{O}(4.0)$ & traces \\
6 & $\mathrm{Co}(\mathrm{OAc})_{2}$ & none & $15 \%$ \\
7 & $\mathrm{Co}(\mathrm{OAc})_{2}$ & $\mathrm{Mg}(\mathrm{OTf})_{2}(1.0)$ & $42 \%$ \\
8 & $\mathrm{Co}(\mathrm{OAc})_{2}$ & $\mathrm{Mg}(\mathrm{OTf})_{2}(1.0)+\mathrm{H}_{2} \mathrm{O}$ & $93 \%(84 \%)^{\mathrm{b}}$ \\
& & $(1.0)$ & $\mathbf{9 6 \%}(\mathbf{8 8} \%)^{\mathrm{b}}$ \\
\hline
\end{tabular}

a NMR yield determined using 1,3,5-trimethoxybenzene as internal standard. ${ }^{b}$ Isolated yield. ${ }^{c}$ Reaction performed under nitrogen.

Isolation of Reaction Intermediates. A detailed study of the reaction of 2a-OAc with EDA under anhydrous conditions was performed. When 2a-OAc was reacted with 2.0 equiv of EDA at $100^{\circ} \mathrm{C}$ for 15 minutes, HRMS analysis showed a single peak at $\mathrm{m} / \mathrm{z}=442.1183$ (Figure S48), corresponding to the molecular formula $\left[\mathrm{C}_{21} \mathrm{H}_{25} \mathrm{CoN}_{3} \mathrm{O}_{4}\right]^{+}$, suggesting the formation of a putative aryl-Co(III)-carbene intermediate. Encouraged by this result, this compound (5a-OAc) was analyzed by NMR spectroscopy. A diamagnetic NMR spectrum was obtained, which is consistent with an octahedral $\mathrm{Co}(\mathrm{III})$ low spin species. Moreover, a singlet at a chemical shift of $5.81 \mathrm{ppm}$ precluded the presence of a $\mathrm{Co}(\mathrm{III})$-carbene species (Figure S41), as the $\alpha$ proton of the carbene moiety is known to be strongly deshielded. ${ }^{3 b}$ Attempts to unravel the nature of 5a-OAc have been pursued by crystallographic analysis without success. Nevertheless, suitable crystals for XRD analysis were obtained by replacement of the acetate anion with $p$-substituted benzoate. Reaction of $\mathbf{2 a - O B z - R}(\mathrm{R}=\mathrm{OMe}, \mathrm{Cl})$ with EDA caused a rapid color change from red to orange, and recrystallization in $\mathrm{CHCl}_{3} /$ pentane afforded $85-97 \%$ yield of orange crystals corresponding to $\mathbf{5 a}-\mathbf{X}(\mathrm{X}=\mathrm{OBz}-\mathrm{Cl}$, OBz-OMe, Figure 1).
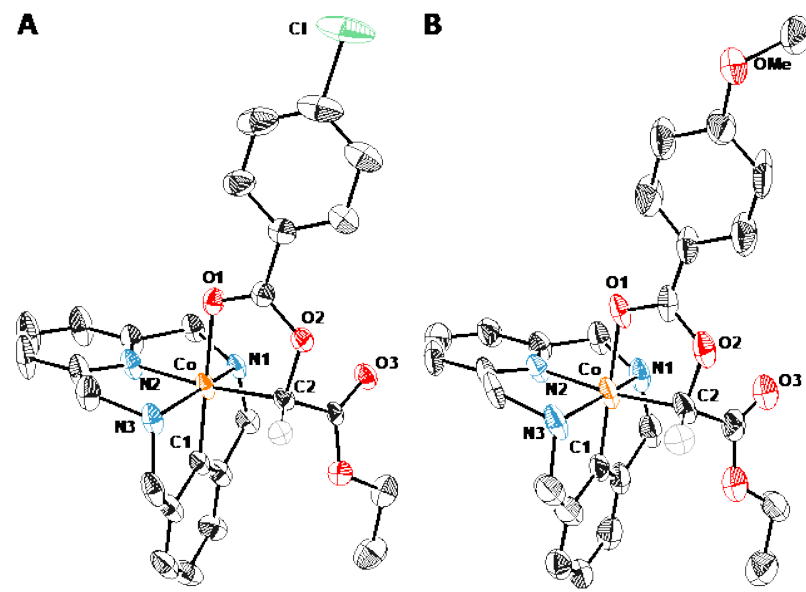

Figure 1. Crystal structures of 5a-OBz-R complexes. (A) 5aOBz-Cl. Selected bond distances $[\AA]$ and angles []ㄹ: $\mathrm{Co}-\mathrm{C}(1)$ 1.846(3), Co-C(2) 1.972(5), Co-N(2) 1.891(4), Co-O(1) 2.008(3); C(1)-Co-C(2) 95.71(2). (B) 5a-OBz-OMe. Selected bond distances $[\AA]$ and angles [ $\left.{ }^{\circ}\right]$ : $\mathrm{Co}-\mathrm{C}(1) 1.84(1), \mathrm{Co}-\mathrm{C}(2)$ 1.97(1), Co-N(2) 1.878(8), Co-O(1) 2.004(7); C(1)-Co-C(2) 96.3(4)-atoms, anions and solvent molecules have been omitted an only one of the enantiomers is depicted for clarity; ellipsoids displayed at 50\% (5a-OBz-Cl) and 30\% (5aOBz-OMe) probability.

Strikingly, the solid-state structures showed an Oh aryl$\mathrm{Co}(\mathrm{III})$ center bearing a carbonyl and a chiral alkyl group as ligands (5a-OBz-R). The formation of $\mathbf{5 a - X}(\mathrm{X}=$ carboxylate) species is rationalized by the trapping of the electron demanding $\mathrm{Co}(\mathrm{III})$-carbene through the nucleophilic intramolecular attack of the carboxylate to $\mathrm{C} 2$. Both 5a-OBz-OMe and $5 \mathrm{a}-\mathrm{OBz}-\mathrm{Cl}^{14}$ compounds show spectroscopic features analogous to 5a-OAc, indicating the same structure. In addition, EXAFS analysis of 5aOAc agrees with the structures in Figure 1 and the DFT derived model (see below, Figure 4), showing a metal center having two N/O/C scattering paths at $1.93 \AA$ and four $\mathrm{N} / \mathrm{O} / \mathrm{C}$ scattering paths at $2.05 \AA$ (Figure 2 and Table S9). In addition, the metal $\mathrm{K}$ - pre-edge and rising edge of 5a-OAc occur at $7711.2 \mathrm{eV}$ and $7720.2 \mathrm{eV}$ respectively, consistent with the presence of a $\mathrm{Co}$ (III) center. ${ }^{10}$ An analogous $\mathrm{Rh}$ intermediate $(\mathbf{7 b}-\mathrm{OBz}-\mathrm{Cl}$, Figures S6774) was obtained when the aryl- $\mathrm{Rh}(\mathrm{III})(\mathrm{Cl})_{2}$ complex $6 \mathbf{b}$ $\mathrm{Cl}^{10}$ was reacted with 4.0 equiv of EDA and $\mathrm{Ag}(\mathrm{OBz}-\mathrm{Cl})$ (Scheme S14). Although the formation of organometallic $\mathrm{Rh}(\mathrm{III})$-alkyl species from carbenes is rare, a similar nucleophilic attack to carbenes using half-sandwich Rhcarbene complexes has been recently described. ${ }^{15}$ 

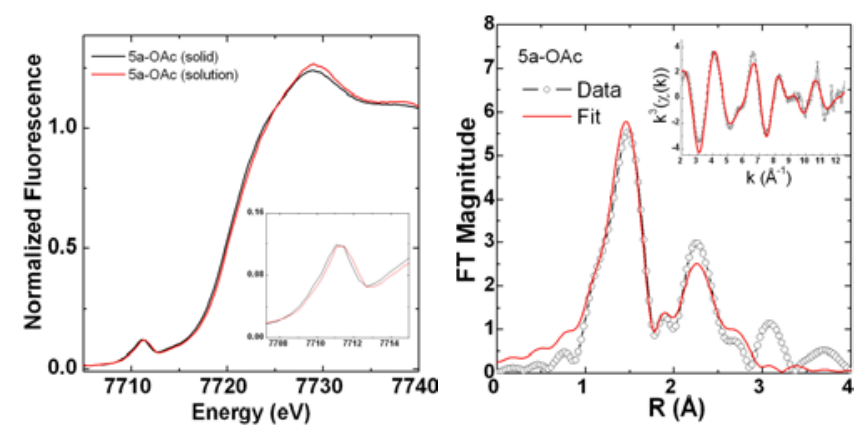

Figure 2. XAS of 5a-OAc. Left: XANES region showing the pelleted sample diluted in boron nitride and the $15 \mathrm{mM}$ solution sample. Right: Fourier-transformed EXAFS spectra fit (inset: $\mathrm{k}^{3}$-weighted unfiltered EXAFS spectra).

Mechanistic Insight. To better understand the role of additives in the formation of cyclic amide 3 , a variety of control experiments was performed starting from 5aOAc. Surprisingly, the isolated aryl-Co(III)-alkyl enolate evolves to product 3 in good yields by addition of water, organic acids and Lewis acids, involving the cleavage of a C-O bond and the formation of a new C-C bond (Scheme 2A and Table S5). As expected, when the same reaction was carried out in absence of additives, poor yields (14\%) were obtained. The enhanced reactivity observed in presence of additives (for instance, with Li(OTf) an $89 \%$ yield of 3 is obtained, Scheme 2A) suggests an activation of the carboxylate group through hydrogen bonding or coordination to Lewis acids, which converts it in a better leaving group. Indeed, when the organometallic aryl-Co(III) complex 2a-TFA, which is bearing an electron-poor carboxylate group such as trifluoroacetate, was reacted with EDA (Scheme 2B), neither isolation nor detection of 5a-TFA by HRMS was achieved and 3 was obtained in $79 \%$ yield in absence of any external additive.

Scheme 2. (A) Evolution of 5a-OAc to 3 with additives and rationalization of the observed reactivity and (B) reactivity of intermediate bearing electron-poor carboxylate 5a-TFA.
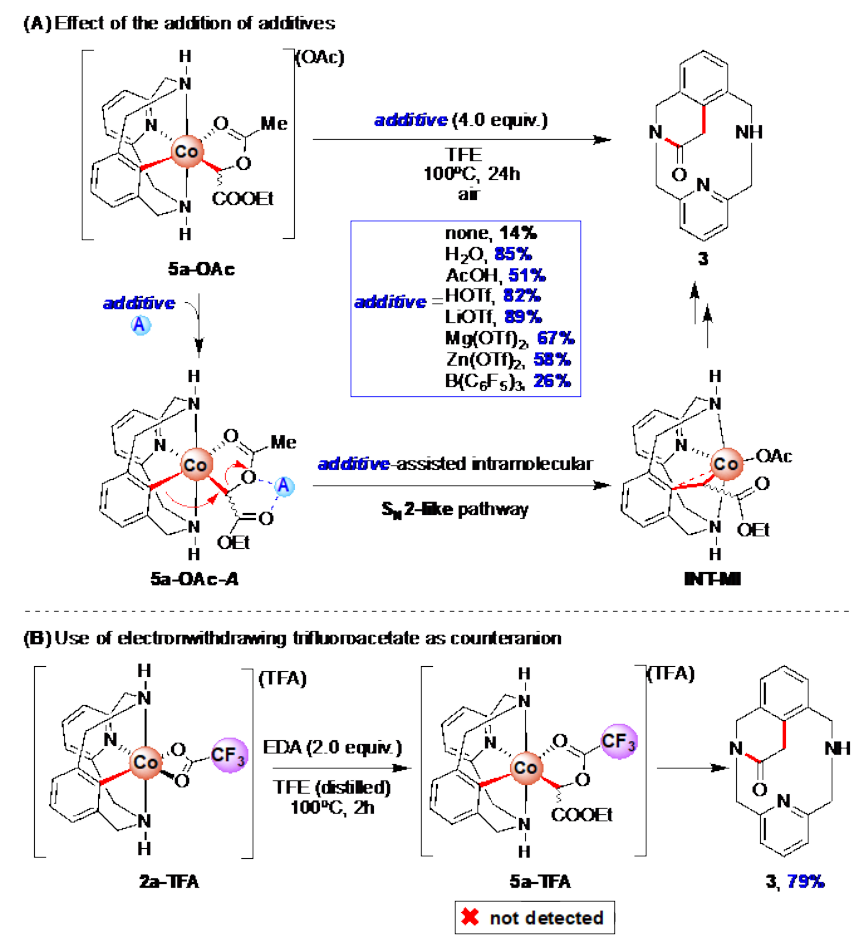

Furthermore, $\mathbf{5 a - X}$ complexes can be used as catalysts (20 mol\%) affording 3 in good yields (Scheme 3A), indicating that organometallic $\mathbf{5 a - X}$ complexes are catalytically active species. In order to test the role of carboxylate anions, dicationic complex $2 \mathbf{a}-\mathrm{CH}_{3} \mathbf{C N}$ was reacted with 2.0 equiv of EDA in TFE at $100{ }^{\circ} \mathrm{C}$ over $24 \mathrm{~h}$ (Scheme 3B and Table S3, entry 5). A complex mixture of decomposition products of EDA was obtained, suggesting the formation of a very reactive, unstable Co(III)carbene intermediate. However, when 2.0 equiv of $\mathrm{NaOAc}$ were added (Table S3, entry 6), 3 was obtained in $41 \%$ yield. We hypothesize that when the Co(III) center is bearing a carboxylate moiety, carboxylate-masked aryl-Co(III) carbenoids species (5a-X) are formed, which highlights the key role of carboxylate anions taming the reactivity of a putative highly electrophilic aryl-Co(III)carbene intermediate.

Scheme 3. (A) Catalysis with $5 a-X$ and (B) role of acetate.

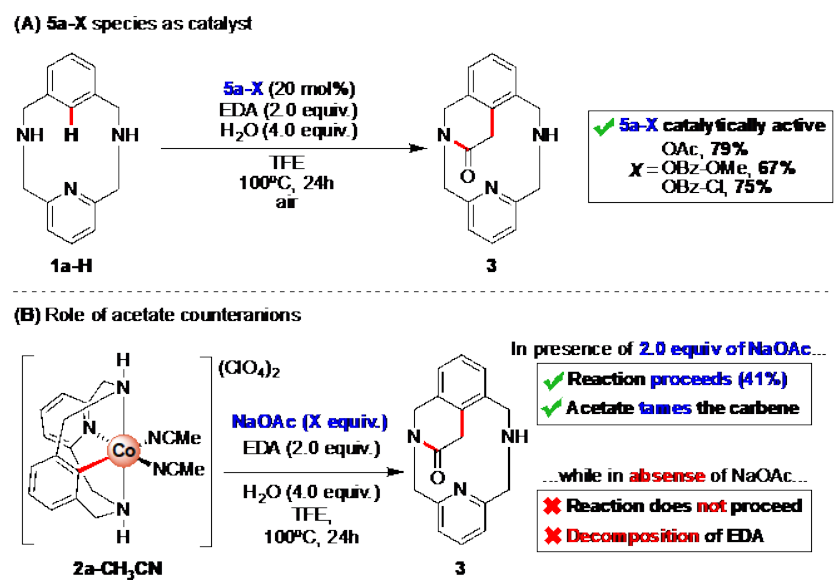


Interestingly, INT-MI (Scheme 2B) could be detected by high-resolution mass spectrometry (HRMS) studies when MS/MS analysis was performed at the mass peak corresponding to $\mathbf{5 a}-\mathbf{X}(\mathrm{X}=\mathrm{OBz}-\mathrm{Cl}$, green; and OBz$\mathrm{OMe}$, red; Figure 3). A single peak, which corresponds to a fragment involving the loss of carboxylic acid ([INTMI-RCOOH $\left.]^{+}=\mathrm{C}_{19} \mathrm{H}_{21} \mathrm{CoN}_{3} \mathrm{O}_{2}{ }^{+} ; \mathrm{m} / \mathrm{z}=382.0970\right)$ was observed, regardless the carboxylate moiety present in the isolated compounds (see also Scheme S11 and Figures S7-9). Relative intensity of INT-MI' at the same collision energy $(15 \mathrm{eV})$ is higher when an electron-poor $p$-substituted benzoate is present in the molecule, supporting the better-leaving-group hypothesis presented above.
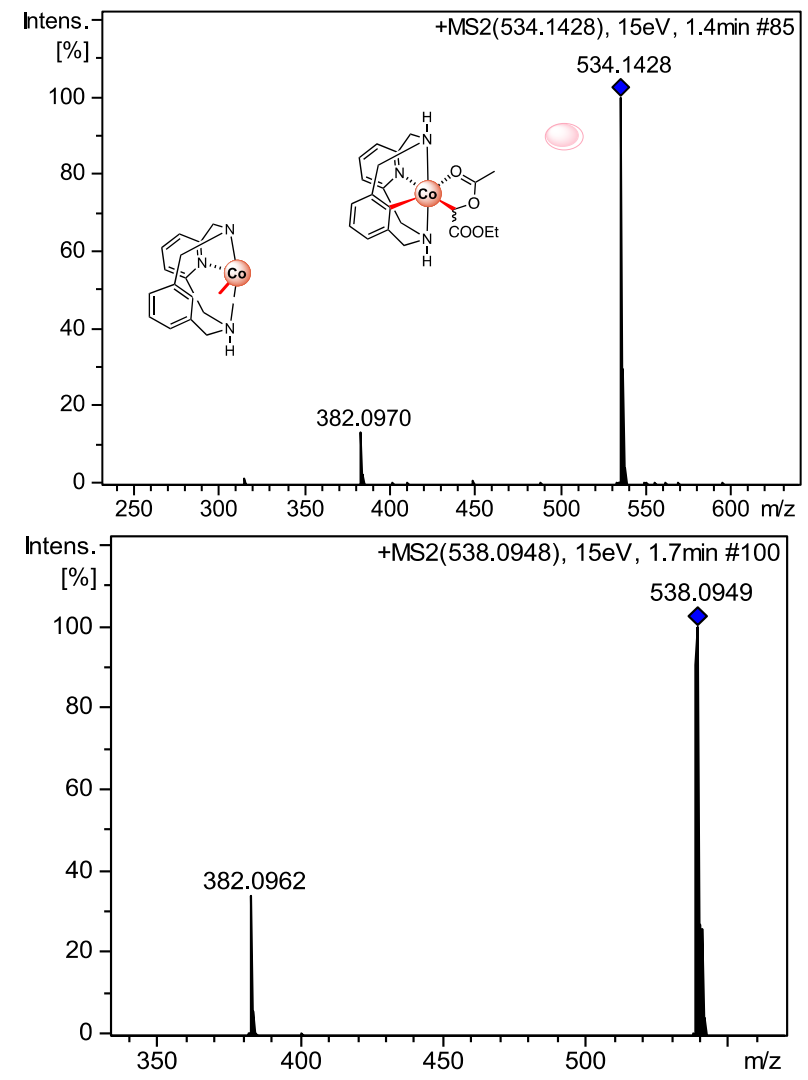

Figure 3. Detection of INT-MI' (experimentally obtained $\mathrm{m} / \mathrm{z}=382.0970$; simulated $\mathrm{m} / \mathrm{z}=382.0960$ ) by $\mathrm{MS} / \mathrm{MS}$ studies of 5a-OBz-OMe $(\mathrm{m} / \mathrm{z}=534.1428$, up) and 5aOBz-Cl (m/z = 538.0949, down) organometallic intermediates.

Further insight on the subsequent proto-demetalation of INT-MI was obtained by D-labeling experiments which results are summarized in Table 3. When 2a-OAc was treated with EDA and 4.0 equiv of $\mathrm{D}_{2} \mathrm{O}$ were added in TFE at $100^{\circ} \mathrm{C}$ (Table 3, entry 1), a $36 \%$ D-incorporation was observed by NMR and HRMS analysis at the $\alpha$ position of the carbonyl group in 3 , in a stereoselective manner (Figures S10-11). Increasing D-incorporation was observed when $\mathrm{H}_{2} \mathrm{O}(65 \%$; table 3, entry 2$)$ and $\mathrm{D}_{2} \mathrm{O}$
(86\%; table 3, entry 3) were added as additives in TFE-d 3 (Figures S12-19).

Table 3. Deuterium-labeling experiments. ${ }^{16}$

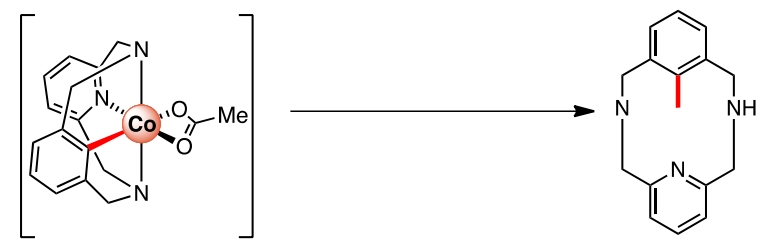

\begin{tabular}{cccc}
\hline entry & additive (equiv.) & solvent & $\begin{array}{c}\text { D-incorporation } \\
(\%)^{\mathrm{a}}\end{array}$ \\
\hline 1 & $\mathrm{D}_{2} \mathrm{O}(4.0)$ & $\mathrm{TFE}$ & $36 \%$ \\
2 & $\mathrm{H}_{2} \mathrm{O}(4.0)$ & $\mathrm{TFE}^{\mathrm{d}} \mathrm{d}_{3}$ & $65 \%$ \\
3 & $\mathrm{D}_{2} \mathrm{O}(4.0)$ & TFE-d & $86 \%$ \\
4 & $\mathrm{Li}(\mathrm{OTf})(1.0)$ & TFE-d 3 & $91 \%$ \\
5 & $\mathrm{Li}(\mathrm{OTf})(1.0)$ & $\mathrm{MeOD}_{3} \mathrm{~d}_{4}$ & $93 \%$ \\
\hline
\end{tabular}

a D-incorporation determined by ${ }^{1} \mathrm{H}$ NMR integration and HRMS analysis.

These results suggest INT-MI is involved in a deuterodemetalation step to furnish INT-PD in a stereoselective manner (Scheme 4), which is a strong evidence of a previous existence of a $\mathrm{C}_{\text {sp3- }} \mathrm{Co}$ (III) bond. Interestingly, $91 \%$ (Table 3, entry 4) and 93\% (Table 3, entry 5) D-labeled 3 was obtained when the reaction was performed in absence of water but using 1.0 equiv of $\operatorname{Li}(\mathrm{OTf})$ in TFE-d 3 (Figure S16-17) and in MeOD-d (Figure S18-19), respectively. These results suggest that Lewis acids may cooperate with the solvent, increasing its acidity as proton source and favoring a plausible proto-demetalation of INT-MI. After this step, as it was described in previously reported studies, INT-PD will evolve to 3 through a LA-assisted cyclization reaction in which $\mathrm{Co}(\mathrm{III})$ or the additive can act as catalysts (Scheme 4). ${ }^{7}$

Scheme 4. Proposed evolution of INT-MI to product 3.
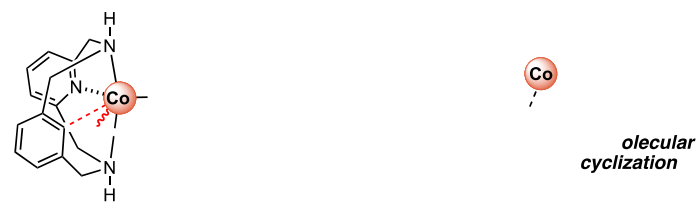

3

Theoretical Studies. DFT studies (See Supporting Information for computational details) of the reaction profile in Figure 4 show that 2a-OAc reacts with EDA to form an adduct (2a-OAc-EDA), in which the carboxylate ligand is now coordinated in a monodentate fashion. Then, 2a-carbene is obtained after a first transition state TS1 $\left(\Delta \mathrm{G}^{\ddagger}=23 \mathrm{kcal} \mathrm{mol}^{-1}\right)$, with the concomitant liberation of $\mathrm{N}_{2}$. However, the transient aryl-Co(III)-carbene falls to the isolated $\mathbf{5 a - O A c}$ organometallic species in an almost barrierless manner (TS2, $\Delta \mathrm{G}^{\ddagger}=0.8 \mathrm{kcal} \mathrm{mol}^{-1}$ ). Indeed, depending on the DFT method, 2a-carbene cannot be 
optimized and TS1 directly evolves to the experimentally isolated 5a-OAc (Figure S23). Therefore, TS1 can be understood as a concerted asynchronous transition state that leads to the formation of the new C-Co and C-O bonds of 5a-OAc species. Then, in absence of additives, 5a-OAc evolves to INT-MI overcoming a barrier of $\Delta \mathrm{G}^{\ddagger}$ $=28.9 \mathrm{kcal} \mathrm{mol}^{-1}$ (TS3). Indeed, TS3 shows the cleavage of the $\mathrm{C}-\mathrm{O}$ bond and formation of the new aryl-C bond in a SN2-type transition state, in which the aryl-Co bond acts as a nucleophile and the acetate acts as a leaving group. Thus, this energetic profile supports the accumulation of 5a-OAc in absence of water $(\Delta \Delta \mathrm{G} \ddagger($ TS3-TS1 $)=$ $\left.5.9 \mathrm{kcal} \mathrm{mol}^{-1}\right)$.

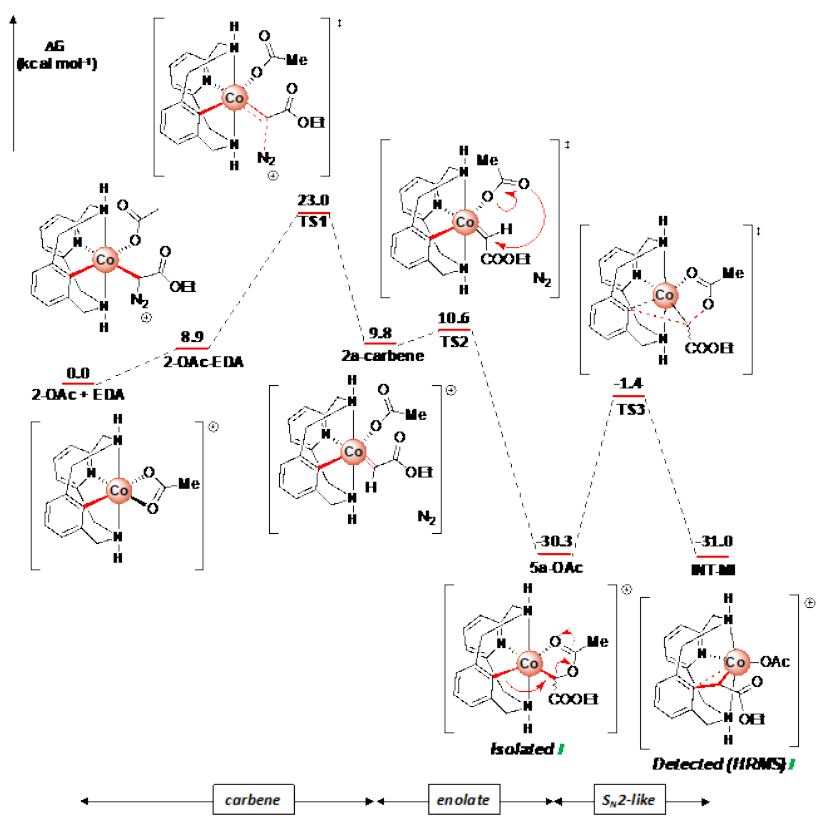

Figure 4. Gibbs energy profile of the reaction. Relative Gibbs energy values are given in $\mathrm{kcal} \cdot \mathrm{mol}^{-1}$.

Water resulted tremendously beneficial for the reaction outcome and therefore we considered the explicit inclusion of a water molecule in the calculations (Figure 5). We hypothesized the nucleophilic character of water could promote its coordination to the $\mathrm{Co}(\mathrm{III})$ centre and enhance its Lewis acid character, favoring the $\mathrm{S}_{\mathrm{N}} 2$-type event. However, when $\mathrm{H}_{2} \mathrm{O}$ is coordinated to 5a-OAc, the carboxylate group is displaced and the overall energy of the resulting complex increases $10.2 \mathrm{kcal} \mathrm{mol}^{-1}$ (5a$\mathrm{OAc}-\mathrm{H}_{2} \mathrm{O}$ ). Then, $5 \mathrm{a}-\mathrm{OAc}-\mathrm{H}_{2} \mathrm{O}$ evolves to INT-MI- $\mathrm{H}_{2} \mathrm{O}$ through the $\mathrm{S}_{\mathrm{N}}$ 2-like pathway with an activation barrier of $\Delta \mathrm{G}^{\ddagger}=33.9 \mathrm{kcal} \mathrm{mol}^{-1}\left(\mathrm{TS} 3-\mathrm{H}_{2} \mathrm{O}\right), 5.0 \mathrm{kcal} \mathrm{mol}^{-1}$ higher than in the absence of water (TS3).

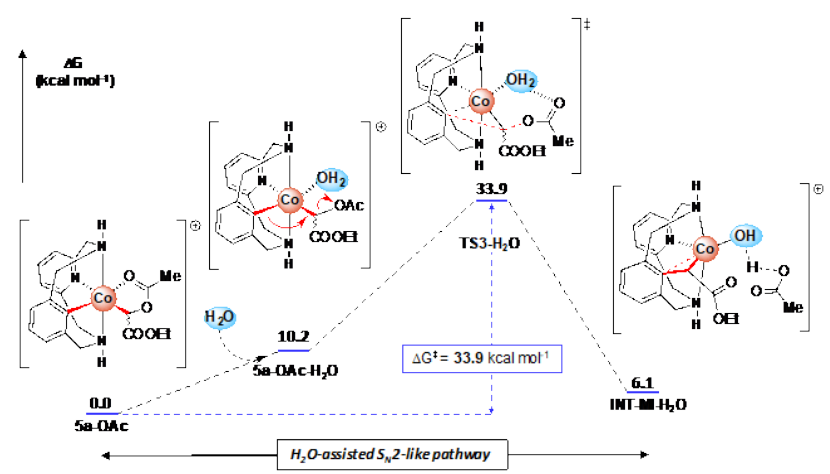

Figure 5. Gibbs energy profile of the $\mathrm{S}_{\mathrm{N}} 2$-type step in presence of $\mathrm{H}_{2} \mathrm{O}$. Relative Gibbs energy values are given in $\mathrm{kcal} \cdot \mathrm{mol}^{-1}$ (see Figure S24 for details).

As the effect an explicit water molecule coordinated to $\mathrm{Co}$ (III) on TS3 was not consistent with the experimental results, the addition of Lewis acids to $\mathbf{5 a} \mathbf{X}$ to obtain 3 was also investigated by DFT (Figure 6). Indeed, in presence of 1.0 equiv of $\mathrm{Li}(\mathrm{OTf})$ in anhydrous conditions, the reaction proceeded in excellent yields (see Table 1, entry 10). Thus, we considered the explicit inclusion of a lithium cation in the computational analysis of the C-O cleavage/C-C bond formation event. Strikingly, when a $\mathrm{Li}^{+}$ion interacts with $\mathrm{O} 2$ and $\mathrm{O} 3$ (see Figure 1), the activation barrier for the $\mathrm{S}_{\mathrm{N}} 2$-like pathway decreases $6.3 \mathrm{kcal}$ $\mathrm{mol}^{-1}\left(\Delta \Delta \mathrm{G}^{\ddagger}=28.9\right.$ (TS3, Figure 4) - 22.6 (TS3-Li, Figure 6) $\left.\mathrm{kcal}^{\mathrm{mol}}{ }^{-1}\right)$. Thus, when Lewis acids are added to the reaction media, they coordinate to the ester moieties in 5a-OAc, turning them into better leaving groups through a LA-mediated carboxylate activation.

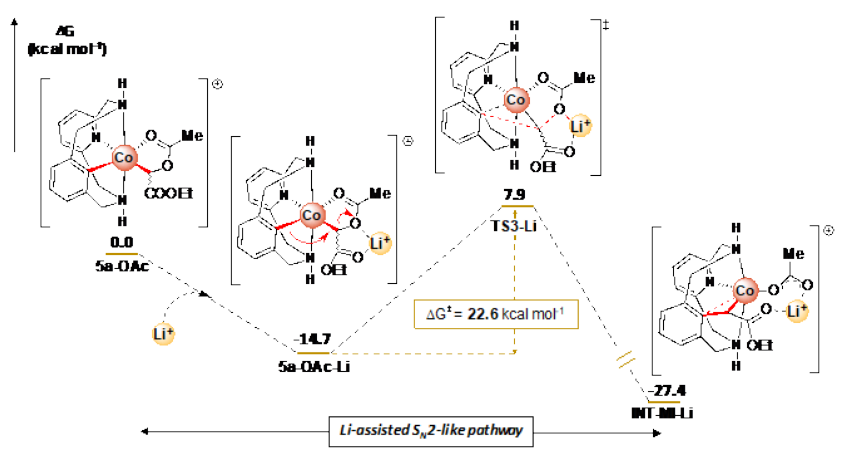

Figure 6. Gibbs energy profile of the $\mathrm{S}_{\mathrm{N}} 2$-like step in presence of $\mathrm{Li}^{+}$. Relative Gibbs energy values are given in $\mathrm{kcal} \cdot \mathrm{mol}^{-1}$ (see Fugure S25 for details).

This result suggests that the interaction of a Lewis acid with 5a-OAc triggers the concomitant C-O cleavage/C-C formation event, probably by turning the carboxylate moiety into a better leaving group. Actually, when a weak base such as trifluoroacetate was used as counteranion (Figure 7), 5a-TFA evolved to INT-MI-TFA overcoming a small activation barrier of $\Delta \mathrm{G}^{\ddagger}=19.7 \mathrm{kcal}$ mol $^{-1}$ (TS3-TFA), which is similar to the barrier obtained 
when 5a-OAc interacts with $\mathrm{Li}^{+}$(Figure 6). Thus, this result supports the beneficial effect of having a better carboxylate leaving group at the $\mathrm{S}_{\mathrm{N}} 2$-type step, as well as the carboxylate-activation observed when Lewis acids such as $\mathrm{Li}^{+}$are present in the reaction media.

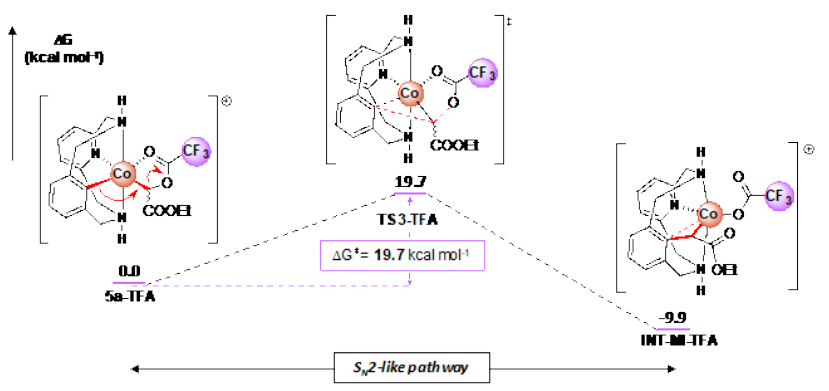

Figure 7. Gibbs energy profile of the $\mathrm{S}_{\mathrm{N}} 2$-type step for 5a-TFA. Relative Gibbs energy values are given in $\mathrm{kcal} \cdot \mathrm{mol}^{-1}$ (see Figure S26 for details).

Then, after the unprecedented Co(III)-mediated intramolecular $\mathrm{S}_{\mathrm{N}} 2$-type $\mathrm{C}-\mathrm{C}$ bond formation in which the carboxylate moiety acts as a relay, INT-MI evolves to 3 through a protodemetalation step and a subsequent LAassisted cyclization, as it has been observed experimentally. Furthermore, these results are supported by previously reported $\mathrm{Co}(\mathrm{III})$-catalyzed protocols. ${ }^{7}$

\section{CONCLUSIONS}

In conclusion, unique C-metalated cis-aryl-Co(III)-alkyl enolate species (5a-X), which can be considered carbenoids, have been synthesized using EDA. Crystallographic, full spectroscopic characterization and theoretical evidences show that masked carbenes $\mathbf{5 a - X}$ are necessary intermediates to deliver the alkyl fragment and elicit the new C-C bond, finally furnishing a 6membered cyclic amide product. To the best of our knowledge, this is the first example of a C-metalated aryl-Co(III)-alkyl enolate engaging in $\mathrm{C}-\mathrm{H}$ functionalization reactions. Moreover, these species are proven to be catalytically active in the synthesis of final product 3 . DFT studies indicate that this transformation occurs through a unique intramolecular $S_{N} 2$-like pathway in which the carboxylate acts as relay. The experimental key role of Lewis acids, particularly $\operatorname{Li}(\mathrm{OTf})$, is reflected in the theoretical studies, unveiling a Li-mediated carboxylate activation that triggers the $\mathrm{C}-\mathrm{O}$ bond cleavage/C-C bond formation event. Efforts on transferring this reactivity to other catalytic systems are currently being performed in our laboratory.

\section{ASSOCIATED CONTENT}

\section{Supporting Information}

The Supporting Information is available free of charge on the ACS Publications website.
Spectroscopic characterization of all compounds, crystallographic data for 5a-OBz-Cl (CCDC 1545619) and 5a-OBzOMe (CCDC 1545620) and computational details.

\section{AUTHOR INFORMATION}

\section{Corresponding Author}

xavi.ribas@udg.edu

\section{Notes}

The authors declare no competing financial interest. Crystallographic data for compounds 5a-OBz-Cl (CCDC 1545619) and 5a-OBz-OMe (CCDC 1545620) can be obtained free of charge from the Cambridge Crystallographic Data Center via www.ccdc.cam.ac.uk/data_request/cif.

\section{ACKNOWLEDGMENT}

We acknowledge financial support from the European Research Council for the Starting Grant Project ERC-2011StG-277801 to X.R. and from MINECO of Spain for project CTQ2016-77989-P to A.C. and X.R., project CTQ2014-52525$\mathrm{P}$ to J.M.L. and project CTQ2015-64436-P to T.P. We also thank Generalitat de Catalunya for projects 2014SGR862 and 2014SGR931. We thank the MECD and MINECO of Spain for a FPU grant to O.P and FPI grant to S.R. X.R. also thanks ICREA for an ICREA Acadèmia award. We acknowledge SOLEIL for provision of synchrotron radiation facilities and we would like to thank Dr. Landrot Gautier for assistance in using beamline SAMBA.

\section{REFERENCES}

(1) a) Su, B.; Cao, Z.-C.; Shi, Z.-J. Acc. Chem. Res. 2015, 48, 886. b) Pototshnig, G.; Maulide, N.; Schnürch, M. Chem. Eur. J. 2017, 23, 9206.

(2) For recent reviews on high-valent cobalt-catalyzed C-H activation, see: a) Yoshino, T.; Matsunaga, S. Adv. Synth. Catal. 2017, 359, 1245; b) Chirila, P. G; Whiteoak, C. J. Dalton Trans. 2017, 46, 9721; c) Wang, S.; Chen, S.-Y.; Yu, X.-Q. Chem. Commun. 2017, 53, 3165. d) Moselage, M.; Li, J.; Ackermann, L. ACS Catal. 2016, 6, 498.

(3) Jia, M.; Ma, S. Angew. Chem. Int. Ed. 2016, 55, 9134.

(4) a) Liu, J.; Hu, L.; Wang, L.; Chen, H.; Deng, L. J. Am. Chem. Soc. 2017, 139, 3876; b) Wang, Y.; Wen, X.; Cui, X.; Wojtas, L.; Zhang, X. P. J. Am. Chem. Soc. 2017, 139, 1049; c) Das, B. G.; Chirila, A.; Tromp, M.; Reek, J. N. H.; Bruin, B. d. J. Am. Chem. Soc. 2016, 138, 8968; d) Lu, H.; Dzik, W. I.; Xu, X.; Wojtas, L.; de Bruin, B.; Zhang, X. P. J. Am. Chem. Soc. 2011, 133, 8518; e) Ikeno, T.; Iwakura, I.; Yamada, T. J. Am. Chem. Soc. 2002, 124, 15152; f) Brookhart, M.; Studabaker, W. B. Chem. Rev. 1987, 87, 411.

(5) a) Fructos, M. R.; Besora, M.; Braga, A. A. C.; Díaz-Requejo, M. M.; Maseras, F.; Pérez, P. J. Organometallics 2017, 36, 172; b) Xia, Y.; Liu, Z.; Feng, S.; Zhang, Y.; Wang, J. J. Org. Chem. 2015, 80, 223; c) Hu, F.; Xia, Y.; Ma, C.; Zhang, Y.; Wang, J. Chem. Commun. 2015, 51, 7986; d) Hu, F.; Xia, Y.; Ye, F.; Liu, Z.; Ma, C.; Zhang, Y.; Wang, J. Angew. Chem. Int. Ed. 2014, 53, 1364; e) Dötz, K. H.; Stendel, J. Chem. Rev. 2009, 109, 3227; f) Davies, H. M. L.; Manning, J. R. Nature 2008, 451, 417.

(6) For characterized Cobalt-carbene species, see: a) Bellow, J. A.; Stoian, S. A.; van Tol, J.; Ozarowski, A.; Lord, R. L.; Groysman, S. J. Am. Chem. Soc. 2016, 138, 5531; b) Mondal, K. C.; Samuel, P. P.; Roesky, H. W.; Carl, E.; Herbst-Irmer, R.; Stalke, D.; Schwederski, 
B.; Kaim, W.; Ungur, L.; Chibotaru, L. F.; Hermann, M.; Frenking, G. J. Am. Chem. Soc. 2014, 136, 1770; c) Harrison, D. J.; Lee, G. M.; Leclerc, M. C.; Korobkov, I.; Baker, R. T. J. Am. Chem. Soc. 2013, 135, 18296; d) Marquard, S. L.; Bezpalko, M. W.; Foxman, B. M.; Thomas, C. M. J. Am. Chem. Soc. 2013, 135, 6018; e) Harrison, D. J.; Gorelsky, S. I.; Lee, G. M.; Korobkov, I.; Baker, R. T. Organometallics 2013, 32, 12; and references therein.

(7) a) Yao, T.; Hirano, K.; Satoh, T.; Miura, M. Angew. Chem. Int. Ed. 2012, 51, 775; b) Zhao, D.; Kim, J. H.; Stegemann, L.; Strassert, C. A.; Glorius, F. Angew. Chem. Int. Ed. 2015, 54, 4508; c) Liu, X.-G.; Zhang, S.-S.; Wu, J.-Q.; Li, Q.; Wang, H. Tetrahedron Lett. 2015, 56, 4093; d) Li, J.; Tang, M.; Zang, L.; Zhang, X.; Zhang, Z.; Ackermann, L. Org. Lett. 2016, 18, 2742; e) Kim, J. H.; Greßies, S.; Glorius, F. Angew. Chem. Int. Ed. 2016, 55, 5577; f) Baek, Y.; Kim, S.; Jeon, B.; Lee, P. H. Org. Lett. 2016, 18, 104. g) Qu, S.; Cramer, C. J. J. Org. Chem. 2017, 82, 1195.

(8) For relevant examples of isolated alkyl- and aryl-Co(III) intermediates through organometallic $\mathrm{C}-\mathrm{H}$ activation, see: a) Maity, S.; Kancherla, R.; Dhawa, U.; Hoque, E.; Pimparkar, S.; Maiti, D. ACS Catal. 2016, 6, 5493; b) Avilés, T.; Dinis, A.; Calhorda, M. J.; Pinto, P. c.; Félix, V.; Drew, M. G. B. J. Organomet. Chem. 2001, 625, 186; c) Kanamori, K.; Broderick, W. E.; Jordan, R. F.; Willett, R. D.; Legg, J. I. J. Am. Chem. Soc. 1986, 108, 7122. e) Broderick, W. E.; Kanamori, K.; Willet, R. D.; Legg, J. I. Inorg. Chem. 1991, 30, 3875.

(9) For examples of macrocyclic organometallic aryl-M compounds isolated and characterized in our group, see: a) Font, M.; Acuña-Parés, F.; Parella, T.; Serra, J.; Luis, J. M.; Lloret-Fillol, J.; Costas, M.; Ribas, X. Nature Commun. 2014, 5, 4373; b) Casitas, A.; King, A. E.; Parella, T.; Costas, M.; Stahl, S. S.; Ribas, X. Chem. Sci. 2010, 1, 326.

(10) Planas, O.; Whiteoak, C. J.; Martin-Diaconescu, V.; Gamba, I.; Luis, J. M.; Parella, T.; Company, A.; Ribas, X. J. Am. Chem. Soc. 2016, 138, 14388.

(11) a) Zhou, W.; Watson, M. B.; Zheng, S.; Rath, N. P.; Mirica, L. M. Dalton Trans. 2016, 45, 15886; b) Zhou, W.; Rath, N. P.; Mirica, L. M. Dalton Trans. 2016, 45, 8693; c) Zhou, W.; Zheng, S.; Schultz, J. W.; Rath, N. P.; Mirica, L. M. J. Am. Chem. Soc. 2016, 138, 5777; d) Zhou, W.; Schultz, J. W.; Rath, N. P.; Mirica, L. M. J. Am. Chem. Soc. 2015, 137, 7604.

(12) For full evaluation of the stoichometric reaction see Table S1.

(13) For full evaluation of catalytic conditions see Table S4.

(14) 5a-OBz-Cl presents a minor conformer in equilibrium with the major species (ratio major/minor $=4: 1$ ) in DMSO-d6 (Scheme S8). However, the major conformer is favored in presence of water and heat, as well as when mixed with 1.0 equiv. of $\mathrm{Zn}(\mathrm{OTf})_{2}$ (Figures S4-6).

(15) Werlé, C.; Goddard, R.; Philipps, P.; Farès, C.; Fürstner, A. J. Am. Chem. Soc. 2016, 138, 3797.

(16) For full spectroscopic and spetrometric data, see Schemes S12-13 and Figures S10-19. 
TOC
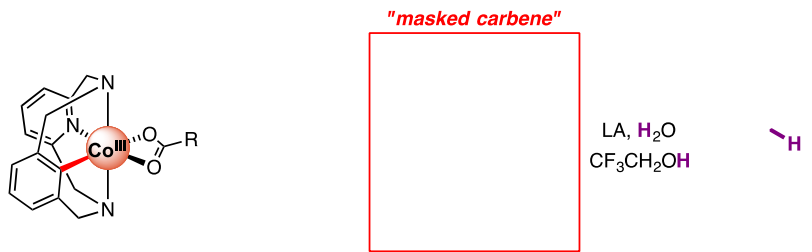

-metalated cis-aryl-Co(III)-alkyl enolate carbenoid

- Complete characterization (XRD, EXAFS, NMR, DFT)

Catalytically active 